\title{
A 48-year-old man with dyspnea, hypoxia and diplopia after gastrectomy
}

\author{
Jianhong Liu, Weizhong Jin* \\ Department of Respiratory Disease, the Hangzhou First People's Hospital, Nanjing Medical University, Hangzhou; Jinhua \\ Guangfu Hospital, Zhejiang Province, China
}

Received: October 1, 2015

DOI: $10.5430 /$ crim.v3n1p4
Accepted: November 12, $2015 \quad$ Online Published: November 20, 2015

URL: http://dx.doi.org/10.5430/crim.v3n1p4

\begin{abstract}
Thiamine deficiency is uncommon in clinical practice. Misdiagnosis may occur because of its greatly varied and nonspecific symptoms, particularly when complicated with primary disorders. We presented a case of thiamine deficiency with multi-organ dysfunction and diplopia after gastrectomy. Supplement of thiamine resulted in the rapidly resolution of his hemodynamic conditions. It's vital important to prevent, recognize and care the condition as soon as possible in healthcare practice.
\end{abstract}

Key Words: Malnutrition, Multi-organ failure, Perioperative period, Thiamine deficiency

\section{INTRODUCTION}

Malnutrition is common in patients with chronic surgical and medical diseases..$^{[1,2]}$ Of which, thiamine deficiency, a life-threatening condition is rarely reported. When encountering the condition, therefore, the emergency and critical care staffs may miss the diagnosis and advisable emergency caring due to its varied, nonspecific presentations, including metabolism disorder, cardiopulmonary failures, and the central and peripheral nervous damages. In the present paper, we reported a case of thiamine deficiency in our hospital in eastern China, complicated with pneumonia, presenting primarily with dyspnea, hypoxia and diplopia.

\section{CASE REPORT}

A 48-year-old man presented with dyspnea and malaise 2 days previously. The patient described the presentation as being persistent, even at rest and exacerbating on exertion. He also reported a significant shortness of breath, diplopia, intractable hiccup and polyuria, but without cough or ex- pectoration. He underwent a radical gastrectomy for gastric cancer a month ago and suffered from an undereating over a 1-month period. His medical history revealed myopia previously, without diabetes and cardiopulmonary diseases. He had never used tobacco or alcohol, was employed as an administration staff. On examination, the patient had temperature of $35.5^{\circ} \mathrm{C}$, with a heart rate of $130-140$ beats $/ \mathrm{min}$, blood pressure of $80 / 26 \mathrm{mmHg}$, a respiratory rate of 32 breathes/min, and an oxygen saturation of $97 \%$ on $10 \mathrm{~L} / \mathrm{min}$ oxygen supplement. He was in a delicate condition. Examination revealed the following: no distention of jugular vein; eyelids twitching slightly; left eyeball in higher position; ocular movement limits; no clubbing, cyanosis, or edema; wheezy phlegm and moist rales by auscultation in both lungs; cardiac regular rhythm. The muscle strength in four limbs is in grade 4 . The remainder of the physical examination was normal.

Results of lab tests are shown in Table 1, potassium, sodium, calcium and creatinine level normal. The urine volume was

*Correspondence: Weizhong Jin; Email: wzkingfdu@ 163.com; Address: 261 Huansha Road, Hangzhou 310006, Zhejiang Province, China. 
$3,700 \mathrm{ml}$ in the last 24 hours. The patient's electrocardiogram showed a sinus tachycardia. A CT pulmonary angiography showed no evidence of a pulmonary embolism, but a patch of infiltrate shown in the left upper lung. Echocardiogram revealed no abnormalities excepting tachycardia. The patient's condition progressively deteriorated after glucose or insulin infusion. However, empiric treatment with thiamine under respiratory and circulatory support resulted in the rapidly resolution of his hemodynamic instability and improvement in his laboratory findings. The pulmonary infiltrates faded soon after initiation of antibiotics.

Table 1. The Lab findings in the case

\begin{tabular}{ll}
\hline Items & Levels (normal values) \\
\hline $\mathrm{pH}$ of artery blood & $7.20(7.35-7.45)$ \\
Oxygenation index & $211(460)$ \\
$\mathrm{PaCO}_{2}$ & $16 \mathrm{mmHg}(35-45 \mathrm{mmHg})$ \\
actual bicarbonate root $(\mathrm{AB})$ & $6 \mathrm{mmol} / \mathrm{L}(22-28 \mathrm{mmol} / \mathrm{L})$ \\
Blood glucose & $25.01 \mathrm{mmol} / \mathrm{L}(6.8-8 \mathrm{mmol} / \mathrm{L})$ \\
$\beta$-hydroxybutyric acid & $197 \mu \mathrm{mol} / \mathrm{L}(60-140 \mu \mathrm{mol} / \mathrm{L})$ \\
lactic acid & $12 \mathrm{mmol} / \mathrm{L}(0.8-1.6 \mathrm{mmol} / \mathrm{L})$ \\
lactate dehydrogenase & $120 \mu / \mathrm{L}(50-240 \mu / \mathrm{L})$ \\
amylase & $296 \mu / \mathrm{L}(0-100 \mu / \mathrm{L})$ \\
serum albumin & $31.2 \mathrm{~g} / \mathrm{L}(45-60 \mathrm{~g} / \mathrm{L})$ \\
blood osmotic pressure & $341 \mathrm{mOsm} / \mathrm{L}(280-310 \mathrm{mOsm} / \mathrm{L})$ \\
hemoglobin & $100 \mathrm{~g} / \mathrm{L}(12-16 \mathrm{~g} / \mathrm{L})$ \\
WBC & $16.4 \times 10^{9} / \mathrm{L}\left(4-10 \times 10^{9} / \mathrm{L}\right)$ \\
platelets & $152 \times 10^{9} / \mathrm{L}\left(100-300 \times 10^{9} / \mathrm{L}\right)$ \\
D-dimmer & $3,820 \mu \mathrm{g} / \mathrm{L}(0-1,000 \mu \mathrm{g} / \mathrm{L})$ \\
creatine kinase MB & $15 \mu / \mathrm{L}(1-25 \mathrm{u} / \mathrm{L})$ \\
troponin I & $0.55 \mu \mathrm{g} / \mathrm{L}(0-0.11 \mu \mathrm{g} / \mathrm{L})$ \\
NT-pro-BNP & $922 \mathrm{pg} / \mathrm{ml}(0-500 \mathrm{pg} / \mathrm{ml})$ \\
\hline
\end{tabular}

\section{Discussion}

Thiamine, that is Vitamin B1, is one of 8 B vitamins. Thiamine deficiency results from an imbalance between the poor dietary intake and increased losses or consumptions. It may occur in all the poorly nourished, malignant patients and alcoholics who may need to be given thiamine and other B vitamins particularly before receiving glucose injection. ${ }^{[3]} \mathrm{A}$ prospective cohort study conducted in 202 children showed a low blood thiamine concentrations upon admission to ICU were detected in 57 patients $(28.2 \%){ }^{[4]}$ The reported incidence of deficiency in adults upon emergency admission to hospital is $21 \% .^{[5]}$ The patient in the present report had suffered from a long-term eating disorder due to gastric cancer and operation. Thiamine is found in a wide variety of foods, such as whole-grain, enriched cereals and rice. Daily recommendations for dietary vitamin $\mathrm{B} 1$ according to the USA National Academy of Sciences are $1.1 \mathrm{mg}$ and $1.2 \mathrm{mg}$ for adult women and men, respectively.

The most widely used test of thiamine status is measurement of the activity of the dependent enzyme transketolase in red cells and its increase when additional thiamine is added. However these tests may not identify all of those with or at risk of severe deficiency and in the emergency situation thiamine should be administered as soon as possible according to the clinician's judgments.

Thiamine is involved in a variety of glucose metabolismrelated and neurological functions. After modification in the body to a diphosphate form, thiamine functions as a cofactor for several enzymes, which are needed for carbohydrate, lipid and amino acid metabolism as well as the maintenance of the protective myelin nerve sheath. Depending on the level of thiamine deficiency, symptoms can vary greatly, ${ }^{[6]}$ classified in Table 2.

The patient in the report suffered from acute beriberi and presented with an acute respiratory failure, acute cardiac failure, metabolic acidosis and cranial nerve palsy. The underlying mechanism of respiratory failure induced by thiamine deficiency in the case, in my opinion, is the weakness of respiratory muscles or the intrapulmonary arteriovenous shunt.

Table 2. The varied presentations in thiamine deficiency

\begin{tabular}{ll}
\hline Subtypes & Presentations \\
\hline Dry beriberi (endemic neuritis) & $\begin{array}{l}\text { Difficulty in walking, tingling or numbness in hands and feet, loss of tendon reflexes, loss of } \\
\text { muscle function, mental confusion, speech difficulties, pain, nystagmus, diplopia, vomiting, etc. } \\
\text { Rapid appearance of intrapulmonary arteriovenous shunt and acute heart failure, causing } \\
\text { shortness of breath, increased heart rate, dyspnea on exertion, peripheral edema. It is highly fatal } \\
\text { and is known to cause sudden death }\end{array}$ \\
$\begin{array}{ll}\text { The baby develops dyspnea and cyanosis and soon dies of cardiac failure } \\
\text { Werntile beriberi }\end{array}$ & $\begin{array}{l}\text { Wernicke's disease involves damage to the central and peripheral nerves; Korsakoff syndrome } \\
\text { is characterized by memory problems and nerve damage. This combination can lead to a severe } \\
\text { vitamin B1 deficiency }\end{array}$ \\
\hline
\end{tabular}


Notably, the pneumonia in left-upper lobe may induce or exacerbate the thiamine deficiency, and mislead physicians to an etiology in lung. In addition, his presentations resembled the diabetic ketoacidosis, causing hyperglycemia, polyuria, shortness of breath and metabolic acidosis, but with a normal level of ketone bodies. It is essential for converting pyruvate from glucose into acetyl coenzyme A for entry to the Krebs cycle where a thiamine deficit is followed by changes in intermediate metabolism that culminate in lactic acidosis. The metabolic acidosis in the patient, mainly the obvious lactic acidosis, resulted from the disturbed Kreb's cycle, in which the thiamine functions as a cofactor for several enzymes. Both the accumulated lactic acidosis and the disturbed tricarboxylic acid cycle resulted to the hyperglycemia in the patient. These actually strengthen the assertion that the primary etiology of the patient is acute thiamine deficiency.

Thiamine is involved in several enzymes that are important for producing energy. The disorder energy production in muscle was related to the heart failure and diplopia. Multi- faceted management approaches are essential in managing many complex cases post operation.

Considering a wide variety of primary diseases complicated with the thiamine deficiency, and its nonspecific symptoms associated with the condition, the patients may consult different doctors, but diagnosis is often missed. Therefore, the awareness of thiamin deficiency is essential for physicians. This case warns against limiting to the specialty for specialists and highlights the importance of a systemic perspective to pursue a diagnosis. It comes to prevention, it's advisable for healthcare providers to educate and courage patients more intake of raw corps, reasonable cooking, or vitamin B1 tables during critical care. In emergency setting, it's important to collect the past medical histories and presentations, including the diet and nutrition in patients at high risks. Additionally, it's also important to intensively note patients' vital signs and avoid glucose injections before correcting the condition completely.

\section{REFERENCES}

[1] Odencrants S, Bjuström T, Wiklund N, et al. Nutritional status, gender and marital status in patients with chronic obstructive pulmonary disease. J Clin Nurs. 2013; 22(19-20): 2822-9. PMid:23675677 http://dx.doi.org/10.1111/jocn. 12222

[2] Zhang L, Su Y, Wang C, et al. Assessing the nutritional status of elderly Chinese lung cancer patients using the Mini-Nutritional Assessment (MNA(囚)) tool. Clin Interv Aging. 2013; 8: 287-91. PMid:23487488 http://dx.doi.org/10.2147/CIA . S41941

[3] Kittanamongkolchai W, Leeaphorn N, Srivali N, et al. Beriberi in a dialysis patient: do we need more thiamine? Am J Emerg Med. 2013; 31(4): 753. PMid:23399344 http://dx.doi.org/10.1016/j.a jem. 2013.01.013

[4] Lu'cio Fla'vio Peixoto de Lima, Heitor Pons Leite, Jose' Augusto de AC Taddei. Low blood thiamine concentrations in children upon admission to the intensive care unit: risk factors and prognostic significance. Am J Clin Nutr. 2011; 93: 57-61. PMid:21068344 http://dx.doi.org/10.3945/ajcn.2009.29078

[5] Jamieson CP, Obeid OA, Powell-Tuck J. Thiamin, riboflavin and pyridoxine status on emergency admission to hospital. Clin Nutr. 1999; 18: 87-91. http://dx.doi.org/10.1016/S0261-5614(99)8 0057-0

[6] Nakano S, Sujino Y, Tanno J, et al. Inducible intrapulmonary arteriovenous shunt in a patient with beriberi heart. Am J Respir Crit Care Med. 2013; 187(3): 332-3. PMid:23378443 http://dx.doi.org /10.1164/ajrccm.187.3.332

[7] Sechi G, Serra A. Wernicke's encephalopathy: new clinical settings and recent advances in diagnosis and management. Lancet neurol. 2007; 6(5): 442-55. http://dx.doi.org/10.1016/S1474-442 $2(07) 70104-7$ 